\title{
Implementation of a Multi-Gbit/s and GFDM- based Optical-Wireless 5G Network
}

\author{
R. M. Borges ${ }^{1,2,3}$, T. R. R. Marins ${ }^{2}$, M. S. B. Cunha ${ }^{1,3}$, D. H. Spadoti ${ }^{3}$, L. L. Mendes ${ }^{2}$, \\ Arismar Cerqueira S. Jr. ${ }^{1}$ \\ ${ }^{1}$ Lab. WOCA, National Institute of Telecommunications (Inatel), Santa Rita do Sapucai, MG 37540-000 Brazil, \\ arismar@inatel.br \\ ${ }^{2}$ Radiocommunications Reference Center, National Institute of Telecommunications (Inatel), Santa Rita do \\ Sapucai, MG 37540-000 Brazil, luciano@inatel.br \\ ${ }^{3}$ Federal University of Itajubá (UNIFEI), Itajubá, MG 37500-903 Brazil, spadoti@unifei.edu.br
}

\begin{abstract}
We report the implementation of an optical-wireless 5G network based on generalized frequency division multiplexing (GFDM) and multi-Gbit/s communication. Dual-drive MachZehnder modulator was employed, enabling simultaneously RF signals transport using two 5G candidate bands, namely: $26 \mathrm{GHz}$ band for providing a femtocell with $2 \mathrm{Gbit} / \mathrm{s}$ throughput; $700 \mathrm{MHz}$ band for enabling rural access applying a supercell. A vector signal generator provides the broadband $26 \mathrm{GHz}$ signal. The Brazilian GFDM-based 5G transceiver generates the lower-frequency signal, with the advantage of low out-of-band emission. An experimental digital performance analysis illustrates the suitability of the proposed solution to address $5 \mathrm{G}$ requirements.
\end{abstract}

Index Terms - 5G, cellular, GFDM, radio over fiber.

\section{INTRODUCTION}

The fifth-generation $(5 \mathrm{G})$ of wireless communications is predicted to provide novel services and address diverse challenging requirements, such as extremely high throughput for enhanced mobile broadband $(e m B B)$ applications, ultra-reliable low latency (URLL) communications, massive machine-type communication ( $m M T C)$ and long range for the remote area access [1], [2]. Basically, multi-Gbit/s individual user experience, billions of devices and connections due to growth of Internet of things (IoT), as well as reliable and broadband mobile access in rural areas were envisioned. Therefore, a flexible physical layer must support multi-service $5 \mathrm{G}$ networks, convergence of different technologies and innovative modulation schemes [3]-[5].

Multiple waveforms have been presented in the literature and the generalized frequency division multiplexing (GFDM) has been shown as a promising 5G solution in terms of out-of-band (OOB) emission and complexity [6-8]. Essentially, it concerns a non-orthogonal waveform that uses subcarriers and subsymbols for transmitting M-ary quadrature amplitude modulation symbols (MQAM). Another key advantage from GFDM is the flexibility, since this waveform might be modified to cover the fourth-generation (4G) technology [8]. It means GFDM is backwards-compatible with the 
Long Term Evolution (LTE) legacy.

Regarding frequency spectrum, $5 \mathrm{G}$ services are typically considered in at least two categories: sub$6 \mathrm{GHz}$ frequencies, which include the conventional cellular bands; above $6 \mathrm{GHz}$, which includes the millimeter-wave (mm-wave) bands [9]-[11]. Both lower-band and higher-band ranges will be combined into a common system architecture to address user demands. The large amount of unexploited spectrum in the higher-bands is the main reason for the interest in mm-waves, whereas sub-6 GHz bands currently offer channel widths of up $20 \mathrm{MHz}$ that may scale to $100 \mathrm{MHz}$ in future. Another possible outcome would be also employing a band below $1 \mathrm{GHz}$ for long-range communication, which includes IoT coverage for remote or rural areas [9].

In this context, radio over fiber (RoF) technology has been recognized as a reliable and efficient solution for simplifying the $5 \mathrm{G}$ architecture by jointly transporting multiple RF carriers, including mm-waves, from a centralized base station to remote antenna units [12]-[15]. Particularly, we have recently proposed the integration of a developed GFDM transceiver in a RoF system [16], as well as a front-end architecture based on WDM-PON (Wavelength Division Multiplexing - Passive Optical Network) toward 5G networks for simultaneously transmitting baseband and RF signals over fiberoptic links [17]. Both studies have presented digital performance analysis of the RF photodetected signals at photodetector (PD) output, with the aim of demonstrating the applicability of the proposed approaches.

This work is an extended version of our previous publication [16], since it is regarding the implementation of a multi-Gbit/s and GFDM-based 5G optical-wireless network (OWN) capable of providing supercells with $700 \mathrm{MHz}$ band and high-throughput femtocells using $26 \mathrm{GHz}$ band. The OWN implementation has been realized indoor for the higher-frequency and at a public high-school in a rural area for the lower-frequency. Furthermore, reaching $2 \mathrm{Gbit} / \mathrm{s}$ in an OWN is a progress over our previous article [17], in which we had demonstrated $1 \mathrm{Gbit} / \mathrm{s}$ communication.

The manuscript is organized in five sections. Section II presents an overview of the Brazilian GFDM-based 5G transceiver, whereas Section III reports the results of its integration in a RoF system. Section IV is on the concept and experimental results of the multi-Gbit/s and GFDM-based OWN. Finally, Section V discusses the relevant conclusions and future works.

\section{GFDM-BASED 5G TRANSCEIVER}

The Brazilian RF transceiver based on GFDM has been developed by our research group in the last years in the context of CRR Project (Radiocommunications Reference Center), with the purpose of addressing the most-demanding $5 \mathrm{G}$ requirements. Fig. 1 depicts its transmitter and receiver block diagrams. The prototype was implemented in a software defined radio platform for operating at the $700 \mathrm{MHz}$ band, with the goal of favoring long-range applications. Higher frequencies, mainly at mmwaves, suffers from severe propagation losses, thus are attractive for complementary scenarios, 
including microcells, picocells and femtocells.

The GFDM waveform is the core of the $5 \mathrm{G}$ transceiver. The innovative modulation scheme uses a non-orthogonal waveform that transmits $N=M K$ QAM symbols per block, using $M$ subsymbols per subcarrier and $K$ subcarriers. Therefore, the GFDM symbol is defined as

$$
x[n]=\sum_{k=0}^{K-1} \sum_{m=0}^{M-1} d_{k, m} g\left[\langle n-m k\rangle_{N}\right] e^{-\frac{j 2 \pi k n}{K}},
$$

where $d_{k, m}$ is the QAM symbol transmitted at the $k^{\text {th }}$ subcarrier and $m^{\text {th }}$ subsymbol, $g[n]$ is the transmit prototype filter and $\langle(\cdot)\rangle_{N}$ is the modulo $N$ operator [6-8]. The advantage of low OOB emission was one of the main reasons for applying GFDM, since this feature is essential for allowing the coexistence among mobile networks operating with different technologies. Furthermore, the capability of covering LTE waveforms as corner cases makes GFDM even more attractive. For instance, GFDM can cover orthogonal frequency division multiplexing (OFDM) by making $\mathrm{M}=1$, $\mathrm{K}>1$ and $\mathrm{g}[\mathrm{n}]$ as a rectangular pulse. Fig. 2(a) presents GFDM and OFDM spectra in a case where central subcarriers are switched off. One can note the GFDM OOB emission was approximately 25 $\mathrm{dB}$ below that generated by OFDM.

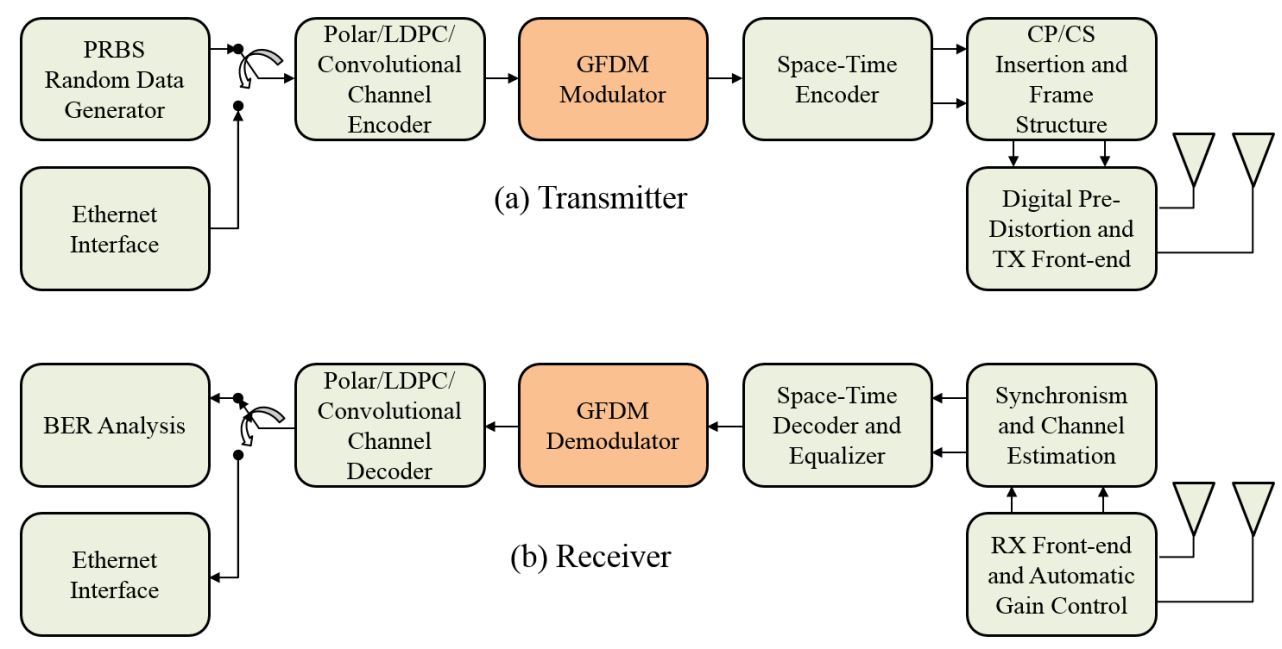

Fig. 1. GFDM-based 5G transceiver block diagram: (a) Transmitter; (b) Receiver.

The developed transceiver employs forward error control (FEC) codes for increasing data robustness against channel communication interferences. It can employ convolutional, low density check parity and polar codes, with rates of $1 / 2,2 / 3,3 / 4$ and 5/6. The modulated signal is applied to a time-reversal space-time coding scheme, in which two correlated versions of the signal are generated. This procedure allows feeding two antennas spaced by several wavelengths in order to make use of diversity gain from multipath channel at reception. A cyclic prefix (CP) and a cyclic suffix (CS) are added to the signals in order to improve robustness against the multipath channel. In addition, a digital pre-distortion (DPD) scheme has been implemented for reducing the non-linear distortions introduced Brazilian Microwave and Optoelectronics Society-SBMO received 2 Oct 2018; for review 12 Nov 2018; accepted 20 Nov 2018 
by electrical amplifiers (EA) at the RF front-end. Fig. 2(b) illustrates the DPD principle by exemplifying EA and DPD amplitude transfer functions, as well as the resultant linearized response. For short, DPD identifies the EA transfer function and imposes an opposite response, aiming the output linear behavior.

In the receiver side, an automatic gain control block normalizes the input level, and after synchronization and channel estimation, the transmitter reverse process is carried out [17]. The GFDM demodulator performs the QAM demapping and delivers the received bits to the channel decoder, which provides only the relevant information to the Ethernet interface. It is worth mentioning that the prototype can operate in burst data transfer mode (BDTM), in which the RF signal is available only when there is useful information to be transmitted, or in continuous data transfer mode (CDTM), when the transmitting antennas are fed all the time. The 2x2 MIMO (multiple input multiple output) feature is also available and the transceiver parameters can be set according to channel conditions or application requirements, including transmission power, number of subcarriers and subsymbols, modulation order, frequency, bandwidth, code rates and periodicity of synchronization.
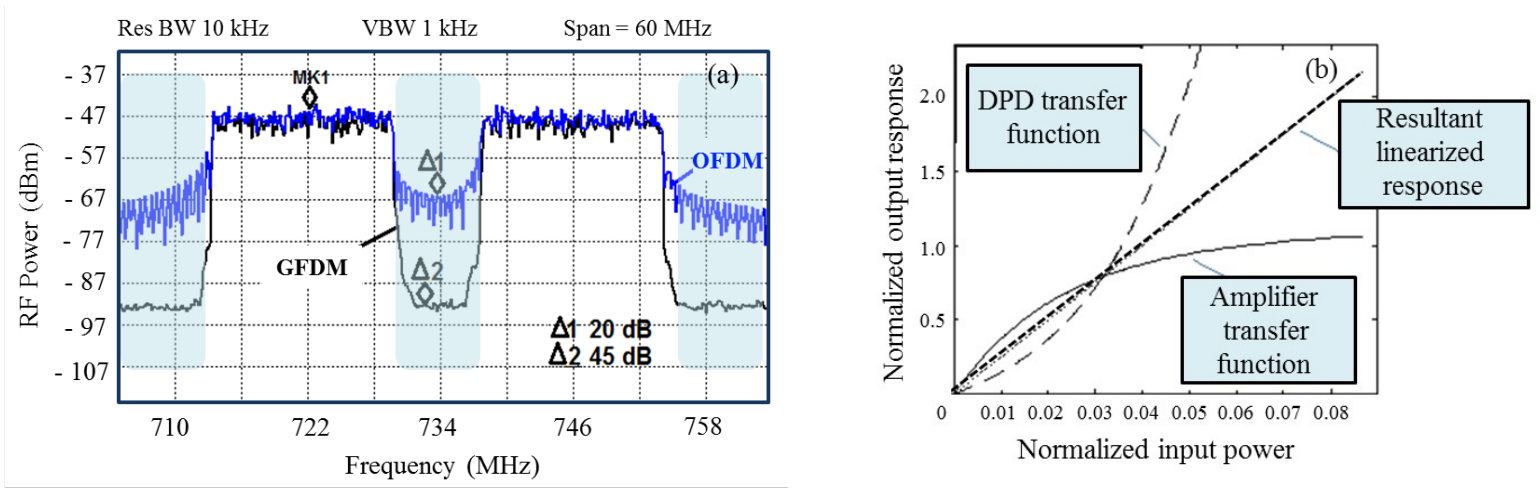

Fig. 2. Comparison between GFDM and OFDM spectra (a) and DPD principle (b).

\section{INTEGRATION OF THE GFDM-BASED 5G TRANSCEIVER IN A RADIO OVER FIBER SYSTEM}

The GFDM-based 5G transceiver was integrated in a RoF system in accordance with the block diagram and experimental setup presented in Figs. 3(a) and 3(b), respectively. The goal was to evaluate its digital performance when using RoF technology for distributing the GFDM signal. The obtained experimental results have been compared to the back-to-back (B2B) configuration, in which the transmitter and receiver were directly connected by using a RF cable. As illustrated in Fig. 3(a), a Mach-Zehnder modulator (MZM) with $8 \mathrm{~dB}$ insertion loss realizes the electro-optical (E/O) conversion, whereas a PIN (P-intrinsic $N$ diode) photodetector with $0.6 \mathrm{~A} / \mathrm{W}$ responsivity performs the reverse process $(\mathrm{O} / \mathrm{E}$ conversion). A continuous wave $(\mathrm{CW})$ laser diode $(\mathrm{LD})$ at $1555.35 \mathrm{~nm}$ provides an $11 \mathrm{dBm}$ optical carrier to MZM, which is driven by the GFDM RF-driven signal and biased at $V_{\text {bias }}=2.5 \mathrm{~V}$. In this way, MZM is set at quadrature point for avoiding distortions. The modulated field is launched into $12.5 \mathrm{~km}$ of single mode fiber (SMF) as an optical fronthaul and the Brazilian Microwave and Optoelectronics Society-SBMO received 2 Oct 2018; for review 12 Nov 2018; accepted 20 Nov 2018 
$\mathrm{O} / \mathrm{E}$ conversion enables recovery of the GFDM signal in the electrical domain. Electrical and/or optical amplifiers can be used to compensate power loses imposed by the RoF system, although the second option has not been exploited in this work. Finally, the GFDM receiver realizes the GFDM digital performance evaluation in terms of modulation error ratio (MER). MER [18] is a performance metric to quantify the digital modulation quality and is typically calculated by $10 \log \left(\left(\sum_{\mathrm{N}}\left|\mathrm{S}_{\mathrm{M}}-\mathrm{S}_{\mathrm{R}}\right|^{2}\right) /\left(\sum_{\mathrm{N}}\left|\mathrm{S}_{\mathrm{R}}\right|^{2}\right)\right)$, where $\mathrm{S}_{\mathrm{M}}$ and $\mathrm{S}_{\mathrm{R}}$ are the measured and reference signals, respectively.

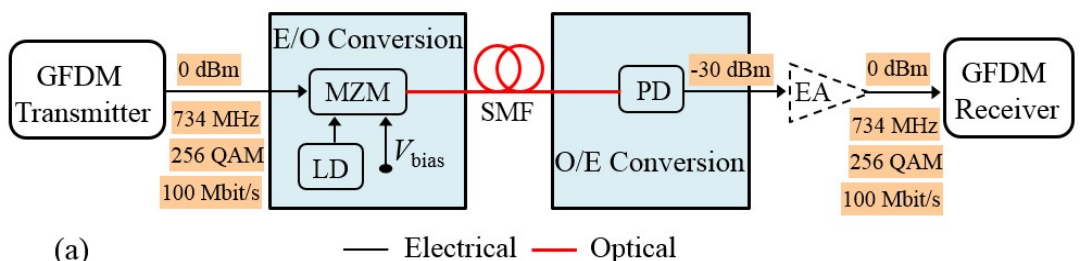

(a)

— Electrical — Optical

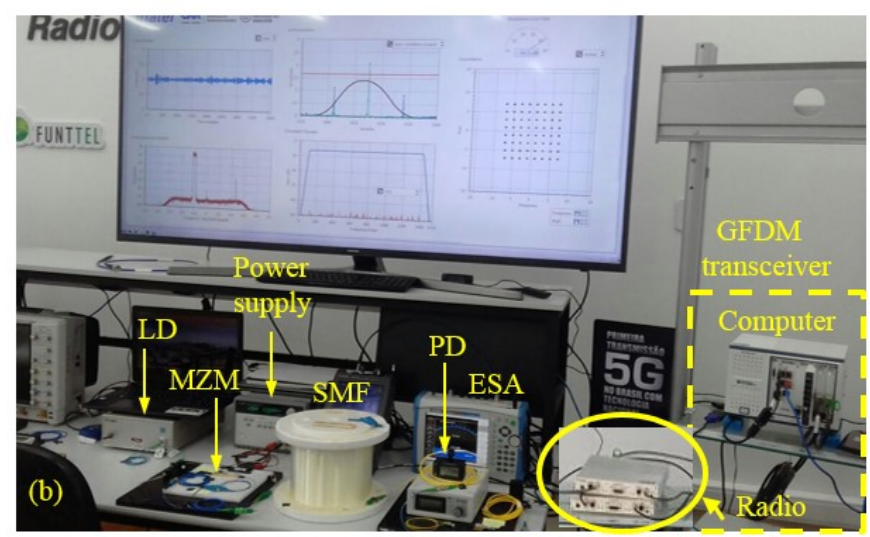

Fig. 3. Integration of the GFDM-based 5G transceiver in RoF system: (a) block diagram; (b) Photography of the experimental setup. LD-laser diode; MZM-Mach-Zehnder modulator; SMF-single mode fiber; PD-photodetector; ESAelectrical spectrum analyzer.

The experiment was configured by using LabVIEW Communications as follows: $734 \mathrm{MHz}$ center frequency, GFDM signal with 256-QAM symbols, bit rate of $100 \mathrm{Mbit} / \mathrm{s}, \mathrm{CDTM}$ and polar code with rate of 5/6. Fig. 4(a) reports the received MER as a function of the GFDM transmitter output power $\left(\mathrm{P}_{\mathrm{RF}}\right)$, after photodetection and without using $\mathrm{RF}$ amplification. One can note both $\mathrm{B} 2 \mathrm{~B}$ and RoF configurations resulted in MER close to $40 \mathrm{~dB}$ from -20 to $-4 \mathrm{dBm}$ power levels, despite the RoF output power ( $\left.\mathrm{P}_{\mathrm{RFout}}\right)$ was $30 \mathrm{~dB}$ below from that of $\mathrm{B} 2 \mathrm{~B}\left(\mathrm{P}_{\mathrm{RFout}}=\mathrm{P}_{\mathrm{RF}}-30 \mathrm{~dB}\right)$ mainly due to the $\mathrm{E} / \mathrm{O}$ and $\mathrm{O} / \mathrm{E}$ conversion losses. This RF power decrement has not penalized the MER parameter, because the signal-to-noise ratio (SNR) was kept above $45 \mathrm{~dB}$ for $\mathrm{P}_{\mathrm{RF}} \leq-4 \mathrm{dBm}$. On the other hand, the MER decreases in the RoF system for higher power levels due to modulation and photodetection process, which starts to generate undesired intermodulation components [19]. For instance, Fig.4(a) shows a reduction of $4.5 \mathrm{~dB}$ for $\mathrm{PRF}=0 \mathrm{dBm}$ and only $\quad 0.6 \mathrm{~dB}$ for $\mathrm{P}_{\mathrm{RF}}=-5 \mathrm{dBm}$.

The use of a $30 \mathrm{~dB}$ electrical amplifier at the PD output for mitigating the RoF system conversion losses made possible to keep the MER close to $40 \mathrm{~dB}$ for $\mathrm{P}_{\mathrm{RF}} \leq-9 \mathrm{dBm}$, as reported in Fig. 4(b). 
Higher power levels, e.g. $0 \mathrm{dBm}$, lead to an SNR reduction (inset iii) and additional MER degradation, which comes from the EA noise figure and nonlinear distortions. However, the DPD use has reduced the nonlinearities and enabled reaching $\mathrm{SNR}=44.5 \mathrm{~dB}$ and $\mathrm{MER}=38.2 \mathrm{~dB}$ for $\mathrm{P}_{\mathrm{RF}}=0$ dBm, as shown in Fig. 4(c). The 256-QAM constellation presents some omitted symbols because the pseudo-random sequence starts every two symbols and it is insufficient to form all binary combinations. Nevertheless, this does not hamper the digital performance analysis, since the missing symbols are not accounted for the MER estimation.
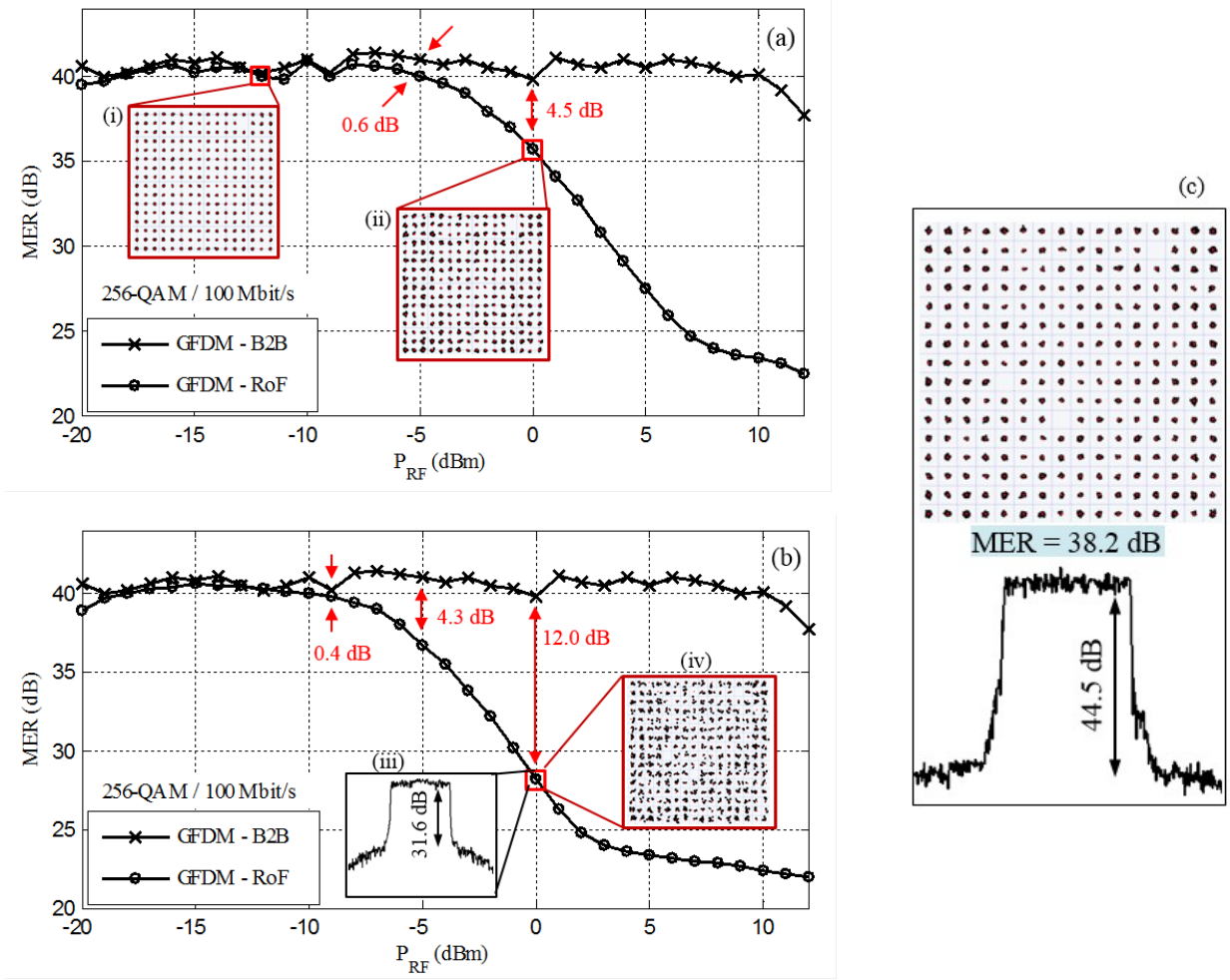

Fig. 4. Digital performance analysis at $100 \mathrm{Mbit} / \mathrm{s}$ : (a) MER as a function of RF power without using EA; (b) MER as a function of RF power by using a $30 \mathrm{~dB}$ EA at PD output; (c) Constellation and received electrical spectrum for

$P_{\mathrm{RFout}}=0 \mathrm{dBm}$ with DPD on. The insets i, ii, and iv are constellations, whereas the inset iii refers to an electrical spectrum.

\section{Multi-GBIT/S AND GFDM-BASED OPTICAL-WIRELESS 5G NETWORK}

The proposed multi-Gbit/s and GFDM-based optical-wireless 5G network concept is represented in Fig. 5, which relies on the use of a dual-drive Mach-Zehnder modulator (DD-MZM) for simultaneously modulating an optical carrier $(1560 \mathrm{~nm})$ with the sub-6 GHz and mm-wave signals from the $5 \mathrm{G}$ network. The Brazilian transceiver generates the first $\mathrm{RF}$-driven signal $\left(\mathrm{RF}_{1}\right)$, corresponding to a $0 \mathrm{dBm}$ GFDM signal at $734 \mathrm{MHz}$ with DPD on and a commercial vector signal generator (VSG) provides a $2 \mathrm{dBm} 26 \mathrm{GHz}$ signal, giving rise to the second RF-driven signal $\left(\mathrm{RF}_{2}\right)$. The main advantage of using DD-MZM is to mitigate interferences between $\mathrm{RF}_{1}$ and $\mathrm{RF}_{2}$ that come from the modulation process nonlinearity, since the distinct RF signals are independently modulated 
at its upper and bottom arms, with distinct and optimized bias voltages.

The two RF signals are recovered by using a broadband photodetector (XPDV2150RA) and then separated by a diplexer, after being distributed by a $12.5 \mathrm{~km}$ optical link. Subsequently, electrical amplifiers are applied for both bands in order to increase the power to be radiated by the antennas, namely: $9 \mathrm{dBi}$ gain Yagi-Uda and panel antennas for the transmission and reception in the lowerband, respectively; 25 and $13 \mathrm{dBi}$ gain horn antennas for the transmission and reception in the higherband, respectively. In this way, a rural supercell has been implemented using the $734 \mathrm{MHz}$ signal, whereas a high throughput indoor femtocell has been realized in the $26 \mathrm{GHz}$ band. Fig. 6 displays photographs of the OWN implementation, including indoor and rural outdoor environments. A vector signal analyzer (VSA) and a second GFDM transceiver were used for evaluating the received RF signals.

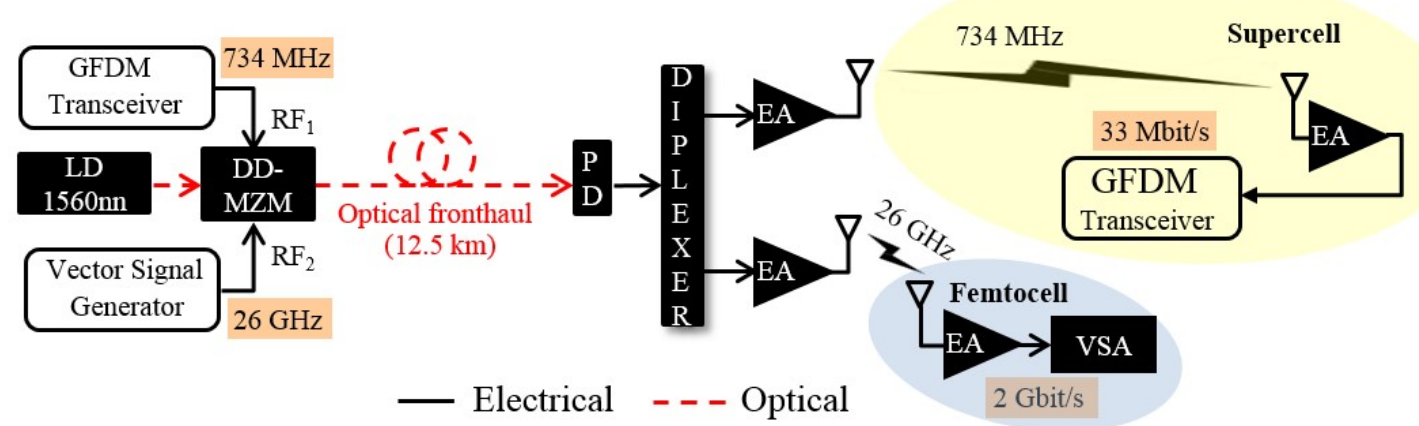

Fig. 5. Multi-Gbit/s and GFDM-based optical-wireless 5 G network concept. DD-MZM- dual-drive Mach-Zehnder modulator; EA- electrical amplifier; VSA-vector signal analyzer.
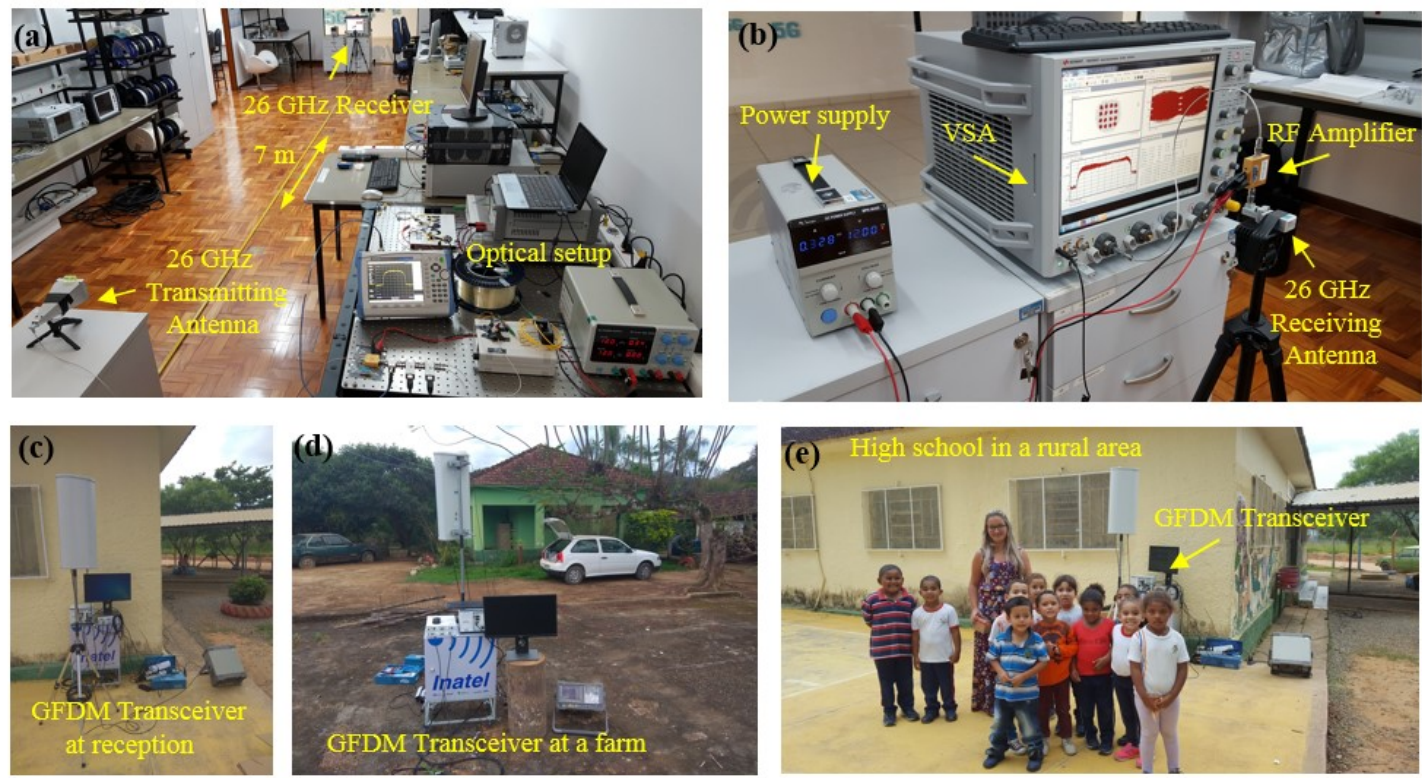

Fig. 6. Photographs of the OWN implementation: (a) Indoor environment; (b) Zoom-in view of the indoor receiver side; (c) and (e) GFDM transceiver at a high school in a rural area; (d) GFDM at a farm. 
The investigation of the higher-band performance has been conducted in terms of error vector magnitude (EVM) by considering 16-QAM signals with bit rates of 1 and $2 \mathrm{Gbit} / \mathrm{s}$, which results in occupied bandwidth of 287.5 and $575 \mathrm{MHz}$, respectively. A B2B analysis indicated the minimum EVM $_{\text {RMS }}$, specifically: $2.7 \%$ for $1 \mathrm{Gbit} / \mathrm{s} ; 8.3 \%$ for $2 \mathrm{Gbit} / \mathrm{s}$. Fig. 7 reports the received spectrum and digital performance evaluation of the indoor femtocell operating at $26 \mathrm{GHz}$ with $2 \mathrm{Gbit} / \mathrm{s}$ over $7 \mathrm{~m}$ range. The 16-QAM constellation is feasible to be demapped, implying in SNR of approximately $14.5 \mathrm{~dB}$ and $\mathrm{EVM}_{\mathrm{RMS}}$ of $13.8 \%$, despite the last one exceeds in $1.3 \%$ the minimum $\mathrm{EVM}_{\mathrm{RMS}}$ requirement (12.5\%) defined by the 3GPP (3rd Generation Partnership Project) [20]. However, the obtained $\mathrm{EVM}_{\mathrm{RMS}}$ might be further reduced by adding DPD in the VSG, since this feature can reduce the amplifier's nonlinear distortions and reduce the optimum $\mathrm{EVM}_{\mathrm{RMS}}$ to lower than $8.3 \%$. Therefore, DPD employment at $26 \mathrm{GHz}$ band is going to be exploited as a future work and might be a potential solution toward a multi-Gbit/s communication in accordance with the $3 \mathrm{GPP}$ specifications. EVM $\mathrm{RMS}_{\mathrm{R}}$ of 7.8 and $9.5 \%$ have been obtained for $1 \mathrm{Gbit} / \mathrm{s}$ in the femtocell with 7 and $9 \mathrm{~m}$ range, respectively, which are in accordance to the $3 \mathrm{GPP}$ requirement.

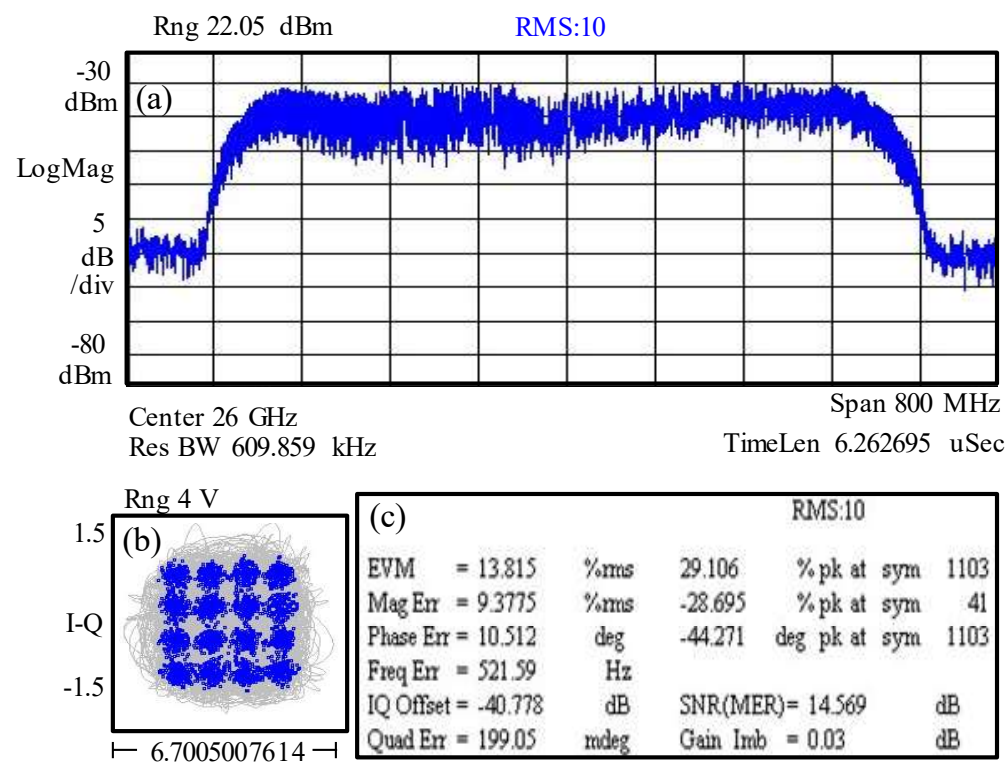

Fig. 7. Analysis of the $2 \mathrm{Gbit} / \mathrm{s}$ signal at $26 \mathrm{GHz}$ in the femtocell with $7 \mathrm{~m}$ range: (a) Electrical spectrum; (b) Constellation; (c) EVM measurement.

The figures of merit of the GFDM-based supercell deployment were: SNR; constellation; MER; throughput; bit error rate (BER). Fig. 8 reports the experimental results of a 256-QAM GFDM signal with $6 \mathrm{MHz}$ bandwidth received at a public high school in a rural area, without commercial Internet services providers, from the city of Santa Rita do Sapucaí-MG, Brazil. It has been achieved SNR of 30.4 and $32.8 \mathrm{~dB}$, for the receiving antennas 1 and 2 respectively, and MER $=29.7 \mathrm{~dB}$, which resulted 
in $33 \mathrm{Mbit} / \mathrm{s}$ throughput and BER $=0$ for a range of $7.51 \mathrm{~km}$. The MER parameter has been obtained using a LabVIEW Communications tool.

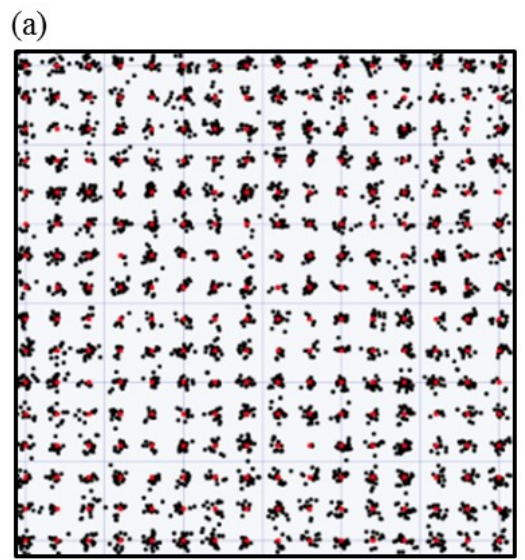

(b)

\begin{tabular}{|ll|}
\hline Rx1_SNRdB & $=30.4 \mathrm{~dB}$ \\
MER & $=29 \mathrm{~dB}$ \\
Rate Meter & $=33 \mathrm{Mbps}$ \\
Signal Channel Power & $=-55.8 \mathrm{dBm}$ \\
Noise Channel Power & $=-93.6 \mathrm{dBm}$ \\
BW & $=6 \mathrm{MHz}$ \\
Bit Error Rate & $=0$ \\
\hline
\end{tabular}

Fig. 8. Analysis of the $734 \mathrm{MHz}$ GFDM signal obtained at a high school in a rural area with $7.51 \mathrm{~km}$ range: (a) Constellation; (b) Performance parameters.

Table I summarizes the obtained performance parameters (bit rate, MER and BER) at the referred high school as a function of the modulation order and code rate. For instance, $22 \mathrm{Mbit} / \mathrm{s}$ was achieved with MER $=31.6 \mathrm{~dB}$ by setting 64-QAM and 3/4 code rate, as well as a MER $=39.7 \mathrm{~dB}$ and $5 \mathrm{Mbit} / \mathrm{s}$ for QPSK (Quadrature Phase Shift Keying) and code rate of 1/2. All evaluated configurations presented BER equal to zero and MER above the 3GPP specified limits, e.g. MER should be higher than $26.9 \mathrm{~dB}$ for 256-QAM [21]. Additionally, the $734 \mathrm{MHz}$ GFDM signal has been evaluated at a farm (Fig. 6(d)) at $11.48 \mathrm{~km}$ distance, by setting 64-QAM and 3/4 code rate, which resulted in reception level of $-61.3 \mathrm{dBm}, \mathrm{MER}=21.3 \mathrm{~dB}$ and $\mathrm{BER}=0$, guaranteeing $22 \mathrm{Mbit} / \mathrm{s}$ communication for such long reach.

TABLE I. SUMMARY OF THE MEASURED PERFORMANCE PARAMETERS AT THE HIGH SCHOOL

\begin{tabular}{cl|ccc}
\hline \multicolumn{5}{c}{ Distance $=7.51 \mathrm{~km}$} \\
\hline $\begin{array}{c}\text { Modulation } \\
\text { order }\end{array}$ & Code & Bit Rate & MER & BER \\
\hline QPSK & Polar 1/2 & $5 \mathrm{Mbit} / \mathrm{s}$ & $39.7 \mathrm{~dB}$ & 0 \\
\hline 64-QAM & Polar 3/4 & $22 \mathrm{Mbit} / \mathrm{s}$ & $31.6 \mathrm{~dB}$ & 0 \\
\hline 256-QAM & Polar 5/6 & $33 \mathrm{Mbit} / \mathrm{s}$ & $29.7 \mathrm{~dB}$ & 0 \\
\hline
\end{tabular}

\section{CONCLUSIONS}

We have successfully implemented and experimentally evaluated a multi-Gbit/s and GFDM-based optical-wireless 5G network, capable to provide a supercell at $734 \mathrm{MHz}$ for rural applications and an 
indoor femtocell at $26 \mathrm{GHz}$ for enhanced mobile broadband applications. A RoF system based on a DD-MZM has been employed for simultaneously transporting the higher- and lower-band 5G candidate signals through a $12.5 \mathrm{~km}$ optical fronthaul. The Brazilian $5 \mathrm{G}$ transceiver has provided a 256-QAM GFDM signal with low OOB emission and DPD, whereas a commercial VSG has generated the wideband $26 \mathrm{GHz}$ signal with 16-QAM. The femtocell provided throughput from 1 to 2 Gbit/s and $\mathrm{EVM}_{\mathrm{RMS}}$ from 7.8 to $13.8 \%$. The supercell at $734 \mathrm{MHz}$ has been implemented in a rural area in order to perform 33 and $22 \mathrm{Mbit} / \mathrm{s}$ throughput at a high-school $(7.51 \mathrm{~km}$ away) and a farm (11.48 $\mathrm{km}$ away), respectively. As a conclusion, the proposed solution represents a promising direction to address multiple services and the tough requirements from the $5 \mathrm{G}$ networks with significantly capital expenditure costs reduction and high network capillarity. Future works regard the use of GFDM and DPD also for the $26 \mathrm{GHz}$ band.

\section{ACKNOWLEDGMENTS}

This work was partially supported by Finep/Funttel Grant No. 01.14.0231.00, under the Radiocommunications Reference Center (CRR), and 5G-RANGE projects. Authors also thank the financial support from CAPES-Finance Code 001, CNPq, RNP and FAPEMIG and technical support from Keysight.

\section{REFERENCES}

[1] Ericsson, "Ericsson mobility report," White Paper, Jun. 2018. [Online] Available: https://www.ericsson.com/assets/local/mobility-report/documents/2018/ericsson-mobility-report-june-2018.pdf.

[2] A. Osseiran, F. Boccardi, V. Braun, K. Kusume, P. Marsch, M. Maternia, O. Queseth, M. Schellmann, H. Schotten, H. Taoka, H. Tullberg, M. A. Uusitalo, B. Timus, and M. Fallgren, "Scenarios for 5G mobile and wireless communications: the vision of the METIS project," IEEE Commun. Mag., vol. 52, no. 5, pp. 26-35, May 2014.

[3] L. Zhang, A. Ijaz, P. Xiao, and R. Tafazolli, "Multi-Service System: An Enabler of Flexible 5G Air Interface," IEEE Commun. Mag., vol. 55, no. 10, pp. 152-159, Oct. 2017.

[4] A. Gupta and R. K. Jha, "A survey of 5G network: Architecture and emerging technologies," IEEE Access, vol. 3, pp. 1206-1232, Jul. 2015.

[5] B. Skubic, G. Bottari, A. Rostami, F. Cavaliere, and P. Öhlén, "Rethinking optical transport to pave the way for 5G and the networked society,” J. Lightw. Technol. vol. 33, no. 5, pp. 1084-1091, Mar. 2015.

[6] J. S. Ferreira, H. D. Rodrigues, A. A. Gonzalez, A. Nimr, M. Matthé, D. Zhang, L. L. Mendes, and G. Fettweis, "GFDM frame design for 5G application scenarios," J. Commun. and Information Systems, vol. 32, no. 1, pp. 54-61, 2017.

[7] D. Zhang, M. Matthé, L. L. Mendes, and G. Fettweis, "A study on the link level performance of advanced multicarrier waveforms under MIMO wireless communication channels," IEEE Trans. Wireless Commun., vol. 16, no. 4, pp. 2350 - 2365, Mar. 2017.

[8] N. Michailow, M. Matthé, I. S. Gaspar, A. N. Caldevilla, L. L. Mendes, A. Festag, and G. Fettweis, "Generalized frequency division multiplexing for 5th generation cellular networks," IEEE Trans. Commun., vol. 62, no. 9, pp. 3045-3061, Sep. 2014

[9] J. Lee, E. Tejedor, K. Ranta-aho, H. Wang, K. Lee, E. Semaan, E. Mohyeldin, J. Song, C. Bergljung, and S. Jung, "Spectrum for 5G: global status, challenges, and enabling technologies," IEEE Commun. Mag., vol. 56, no. 3, pp. 12-18, Mar. 2018.

[10] Qualcomm, "Making 5G NR a reality: leading the technology inventions for a unified, more capable 5G air interface," White paper, Dec. 2016.

[11] Y. Niu, Y. Li, D. Jin, L. Su, and A. V. Vasilakos, "A survey of millimeter wave communications (mmWave) for 5G: opportunities and challenges," Wireless Netw., vol. 21, no. 8, pp. 2657-2676, Nov. 2015.

[12] H. Kim, "RoF-based optical fronthaul technology for 5G and beyond," in Optical Fiber Communications Conference and Exposition (OFC), San Diego, CA, USA, 2018.

[13] B. G. Kim, S. H. Bae, H. Kim, and Y. C. Chung, "RoF-based mobile fronthaul networks implemented by using DML and EML for 5G wireless communication systems," J. Lightw. Technol., vol. 36, no. 14, pp. 2874-2881, Jul. 2018.

[14] A. Chowdhury, H. Chien, S. Fan, J. Yu, and G. Chang, "Multi-band transport technologies for in-building host-neutral wireless over fiber access systems," J. Light. Technol., vol. 28, no. 16, pp. 2406-2415, Aug. 2010.

[15] K. Ikeda, T. Kuri, and K. Kitayama, "Simultaneous three-band modulation and fiber-optic transmission of 2.5-Gb/s baseband, microwave-, and 60-GHz-band signals on a single wavelength," J. Lightwave Technol., vol. 21, no. 12, pp. 3194-3202, Dec. 2003.

[16] R. M. Borges, T. R. R. Marins, M. S. B. Cunha, D. H. Spadoti, L. L. Mendes, and Arismar Cerqueira S. Jr., "GFDM Transceiver Integrated to a Radio over Fiber System for 5G Networks (in Portuguese)," in Proc. $18^{\circ}$ SBMO - Simpósio Brasileiro de Micro-ondas e Optoeletrônica e $13^{\circ}$ CBMAG - Congresso Brasileiro de Eletromagnetismo (MOMAG), Santa Rita do Sapucaí, MG, Brazil, 2018. 
[17] R. M. Borges, T. R. R. Marins, M. S. B. Cunha, H.R.D. Filgueiras, I. F. da Costa, R. N. da Silva, D. H. Spadoti, L. L. Mendes, and Arismar Cerqueira S. Jr., "Integration of a GFDM-based 5G Transceiver in a GPON using Radio over Fiber Technology," IEEE/OSA Journal of Lightwave Technology., vol. 36, no. 19, pp. 4468-4477, Oct. 2018.

[18] ETSI; Digital video broadcasting (DVB); Measurement guidelines for DVB systems, ETSI TR 101290 v1.2.1 (2001-05).

[19] S. Iezekiel, "Microwave photonics, devices and applications," 1st ed. Chichester, United Kingdom: Wiley, 2009, 342 p.

[20] LTE; Evolved Universal Terrestrial Radio Access (E-UTRA); User Equipment (UE) radio transmission and reception (3GPP TS 36.101 version 10.3.0 Release 10), ETSI TS 136101 v10.3.0, 2011.

[21] 3rd generation partnership project; Technical specification group radio access network; Evolved universal terrestrial radio access (EUTRA); Base station (BS) conformance testing (Release 12), 3GPP TS 36.141 v12.7.0, 2015. 